\section{Endocrinología del Embarazo, Parto, Puerperio y Lactancia}

\author{
Dr. Francisco L. García Conti**
}

Los profundos cambios endocrinos que sufre el organismo femenino durante el embarazo y fases subsiguientes, parto, puerperio y lactancia, son unos de los aspectos médicos más debatidos e investigados durante las dos últimas décadas. El nuevo concepto de la unidad feto-placentaria, los adelantos de las técnicas de determinaciones hormonales por radio-inmuno-análisis, las correlaciones hormonales con la patología de la gestación, etc., son, entre otros progresos, los puntos que han marcado una época de gran avance en el estudio de la endocrinología femenina.

El ciclo menstrual, es, simplemente, el preámbulo que prepara la verdadera expresión de la mujer para entrar de lleno a su vida reproductiva, es decir, a lo que se denomina como el ciclo gravídico o gestacional. Este último empieza cuando el óvulo es fertilizado, señalando el comienzo de la verdadera gestación: su implantación en la cavidad uterina. Por consiguiente, describiremos en forma sucesiva la fisiología endocrina del embarazo comprendiendo los crinología fetal, para después entrar a detallar el aspecto relacionado con los mecanismos de la interrupción fisiológica de la gestación y los fenómenos inherentes al puerperio y lactancia.

** Profesor Asociado de Ginecología y Obstetricia, Facultad de Medicina, Universidad Javeriana. Jefe, Sección de Endocrinología Femenina y Esterilidad Conyugal, Hospital Universitario San Ignacio, Bogotá, Colombia.

\section{FISIOLOGIA ENDOCRINA DEL EMBARAZO}

Es un hecho ya conocido que el cuerpo lúteo se forma después de la ovulación, independientemente de que haya ocurrido o no fertilización. Si ésta se produce, el zigote así formado se beneficia de los esteroides luteínicos durante un período de dos semanas (18). La acción endocrina del cuerpo amarillo se manifiesta en dos aspectos fundamentales: a) nutrición tubotrofa del concepto y b) preparación del lecho nidatorio. Hasta que la anidación no se ha realizado, no empieza, endocrinamente , hablando, la gestación. A partir de ese momento tiene lugar la secreción trofoblástica y se produce, como consecuencia de ella, la persistencia activa del cuerpo lúteo.

Un concepto ya revaluado, sostenía que la nutrición del embrión comenzaba con la implantación del blastocisto en el útero. Los experimentos de CHANG (33, 34) parecen probar que existe una sustancia de naturaleza aún desconocida, secretada por la pared tubárica, que es necesaria para que la fertilización se realice normalmente y que nutre a la mórula durante su trayecto a lo largo de la trompa. Parece también que esta secreción es dependiente de la acción de la progesterona.

\section{ENDOCRINOLOGIA DE LA IMPLANTACION}

La implantación se realiza en el humano al séptimo día después de la fertilización, mientras el embrión se encuentra en su estado de blastocisto. Este proceso está re gulado principalmente por la progesterona pero también los estrógenos juegan un papel importante como auxiliares de la anterior. Se cree que los estrógenos producen liberación de histamina la cual en unión con la anhidrasa carbónica alcaliniza el endometrio y favorece la implantación (126). Otras condiciones indispensables para la implantación, son el desarrollo adecuado de las glándulas endometriales y la presencia de la secreción de glicógeno. Antes de que el embrión se haya implantado y durante su primer contacto con el endometrio obtiene su nutrición de la secreción glandular. Durante la fase subsiguiente, el na- 
ciente trofoblasto, horada el estroma endometrial y se nutre por inhibición glicogénica. Una vez que se ha alojado en forma óptima dentro del tejido conectivo del estroma, tiene todavía que desarrollar sus vellosidades coriales y se encuentran en el "estado pre-velloso". La aparición de la primera vellosidad corial coincide con la llamada hemorragia de implantación conocida como "signo placentario de Hartman" el cual ocurre cuando el conceptus tiene, una edad de 15 días o sea cuando "aparece" la primera falla menstrual. Este signo señala el comienzo de la nutrición hemotrófica, completando así el fenómeno de la implantación.

En esta forma, quedan demarcados los límites normales de los fenómenos hormonales iniciales de la gestación. La vellosidad trofoblástica iniciará el desarrollo del corion $\mathrm{y}$, a su debido tiempo, el de la placenta, la cual se impondrá por sí misma como glándula endocrina del embarazo.

$\mathrm{Al}$ mismo tiempo e inmediatamente antes de la primera falla menstrual, el cuerpo lúteo cíclico se convierte en el cuerpo lúteo gravídico por la acción de la gonadotropina trofoblástica la cual, desde este momento, estará presente en la sangre materna. El punto cardinal de este cambio es el hecho de que, desde este momento en adelante, la hipófisis cede al corion el control de la actividad gonadal.

\section{ENDROCRINOLOGIA DE LA PLACENTA}

Es ciertamente interesante el hecho de que la función endocrina de la placenta era completamente desconocida tan recientemente como hace 50 años. El descubrimiento en 1927 de la existencia de grandes cantidades de estrógenos y gonadotropina en la sangre y orina de las embarazadas, condujo a los investigadores a suponer que la placenta era una glándula de secreción interna. Esto puede ahora responderse en una forma inequívoca. Sin embargo, hay varias preguntas que no han podido ser respondidas en una forma completa. Por ejemplo, se desconoce el número y clase de hormonas producidas por la placenta; sus cantidades y su actividad secretora en diferentes especies; pero, sin embar- go, hay un hecho que está generalmente aceptado y es el de que la función endocrina primordial de la placenta, está relacionada con el mantenimiento del embarazo.

Dos amplias categorías de hormonas están identificadas: gonadotropinas de naturaleza proteica, capaces de prolongar las funciones del cuerpo lúteo más allá de su duración de acción usual y esteroides capaces de reproducir muchos de los efectos metabólicos generales característicos del estado gravídico. Por consiguiente, las hormonas placentarias identificadas hasta el presente comprenden por lo menos gonadotropina coriónica, lactógeno placentario estrógenos y progesterona. Secundariamente y de función todavía no completamente definida, se pueden mencionar tambien co mo compuestos posiblemente sintetizados por el tejido placentario, los andrógenos, ciertos corticoides $\mathrm{y}$ las prostaglandinas.

Los esteroides sexuales no son particulares del embarazo, ni de la placenta; por otra parte, la gonadotropina coriónica humana es, aparentemente, una sustancia única, hablando del estado normal, porque, anormalmente, aparece en niveles muy elevados, en la malignización del tejido trofoblástico en ambos sexos.

Consideramos en su órden estos compuestos ya mencionados.

\section{Gonadotropina coriónica. (H.C.G.)}

Hay dudas acerca de cual es la verdadera función de la HCG en la gestación; aunque en los animales inferiores tiene un efecto luteotrópico para mantener el cuerpo amarillo del embarazo, no hay evidencia de que en el humano ésto ocurra (69). En cuanto al sitio de su orígen, hay también dudas. Estudios de anticuerpos fluorescentes han determinado que la HCG está exclusivamente localizada en el sincitio (129), pero se ignora el almacenamiento. Por otra parte, CHARD (36) afirma que se produce en el citotrofoblasto.

La HCG es una glicoproteína con un peso molecular entre 30.000 y 100.000 . Desde el punto de vista de su estructura es diferente de las gonadotropinas hipofisarias porque la porción de carbohidrato de la 
molécula contiene hexosamina y galactosa (69). Es secretada en el embarazo apenas termina la implantación y alcanza los niveles máximos entre el 2o. y 3er. mes. Normalmente es secretada en forma directa a la sangre materna y excretada por el riñón. Se encuentra en mínimas cantidades en la sangre y tejidos fetales. El tamaño molecular de esta hormona es tal que se acerca a los límites de filtración por el glomérulo renal.

\section{Niveles sanguíneos y urinarios.}

Por convenio internacional bajo los auspicios del Comité de la Liga de las Naciones para Standards Biológicos, 1 U.I. de gonadotropina coriónica es la cantidad de actividad equivalente a la correspondiente a 0.1 mg. de un preparado standard. Sobre esta base, las concentraciones séricas en el embarazo tienen un patrón característico, elevándose desde los niveles basales entre $3 \mathrm{y}$ 30 U.I. por c.c. hasta cerca del 140. día después de la primera falla menstrual (alrede- dor del día 26o. después de la fecundación), para alcanzar luego el pico máximo cercano a las 600 U.I. por c.c. entre los días 50o. y 70o. del embarazo (Gráfica $1 \mathrm{~A}$ ), o sea aproximadamente, entre la 7 a. y 10 a. semana de gestación. De allí en adelante, el título comienza a descender rápidamente, llegando a niveles $\tan$ bajos de 5 a 35 U.I. por c.c. hacia el día 90o. del embarazo para seguir así hasta el parto (5). Dentro de las 48 horas posteriores a la expulsión de la placenta, la hormona desaparece del torrente circulatorio.

Los niveles de excreción urinaria reflejan la concentración sérica. La excreción temprana del órden de 5.000 U.I. en 24 horas se elevan rápidamente a niveles máximos con cifras hasta de 500.000 U.I. en 24 horas entre los días 50 a 70 del embarazo para descender luego a niveles constantes de aproximadamente 8.000 U.I. hasta el parto. Tres o cuatro días después del parto, la HCG no puede ser detectada en la orina.

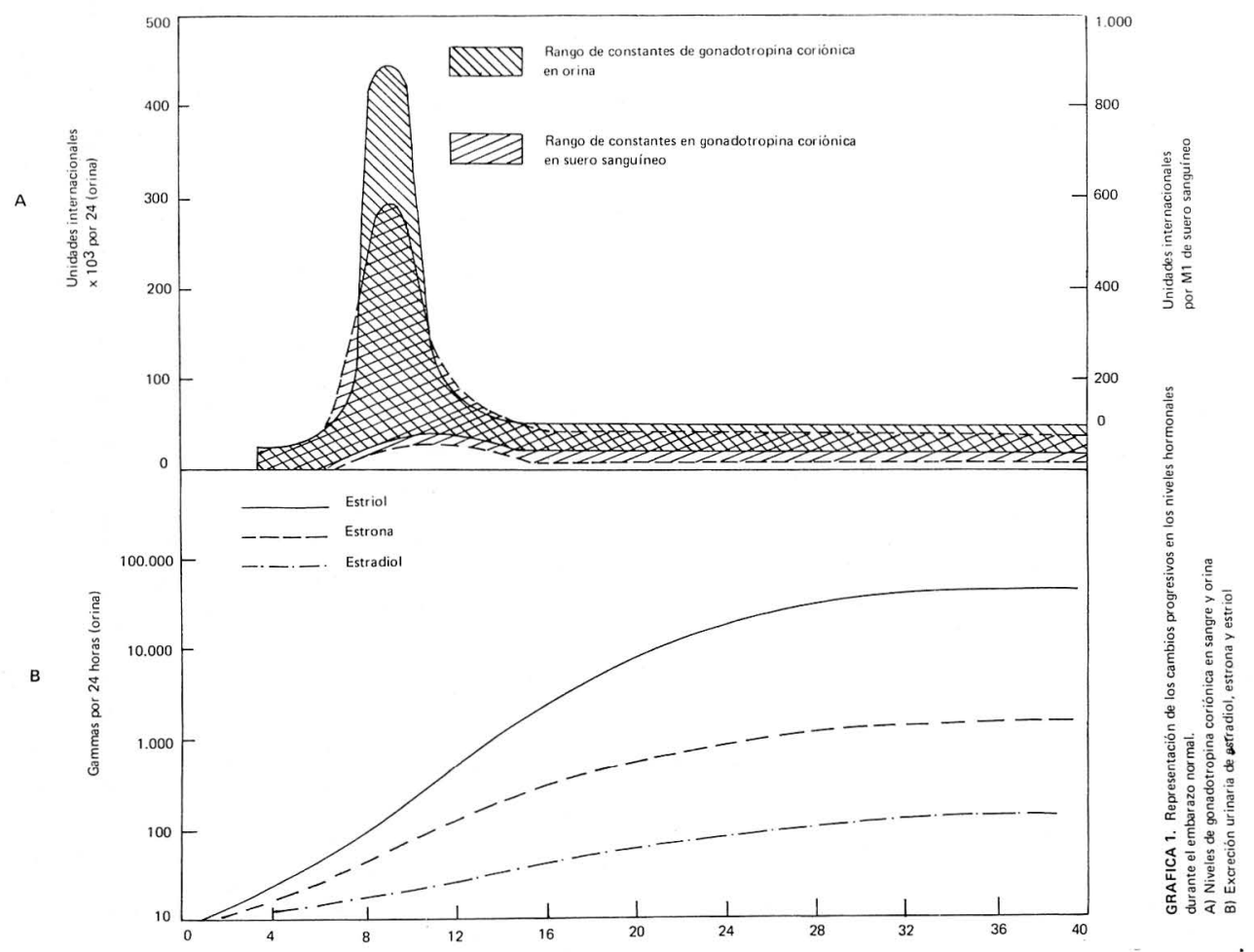




\section{Aplicaciones clínicas.}

La gonodotropina coriónica se puede determinar en plasma o en orina, ya por métodos biológicos o inmunológicos. $\mathrm{La}$ alta axactitud de estas pruebas tienen un rango del 95 a $98 \%$.

El empleo más frecuente de la determinación de HCG es para el diagnóstico del embarazo pues se excreta por la orina en forma temprana, es decir, a los 12 días después de la primera falla menstrual o a los 42 días después de la última regla. También su determinación cuali y cuantitativa tiene amplia utilidad en el diagnóstico de las alteraciones benignas (mola hidatidiforme), o malignas (coriocarcinoma) del trofoblasto, pues en estas entidades se eliminan por la orina altas cifras de HCG. Hoy día se recurre más a la detección de la gonadotropina por métodos inmunológicos que por los biológicos, pues los primeros son mucho más rápidos, como que sólo toma 3 minutos la determinación cualitativa, como también porque son mucho más exactos (62). Las pruebas biológicas todavía tienen algún uso cuando no se dispone de las técnicas inmunológicas. Tienen como base la estimación cualitativa de la HGC en la orina de la supuesta embarazada comprobando sus efectos sobre los ovarios de roedores o sobre las gonadas de amfibios. A título simplemente informativo, describimos brevemente las diferentes pruebas, así:

1. La prueba de ASCHHEIM-ZONDEK en que se utilizan ratas hembras inmaduras y demuestra la formación de folículos hemorrágicos o de cuerpo lúteo en los ovarios.

2. La prueba de FRIEDMAN que emplea conejas maduras no preñadas con el mismo objetivo de la anterior.

3. La prueba de la hiperemia ovárica en la rata, empleando roedores inmaduros y observando una congestión rápida y rojiza característica en las gonadas.

4. La prueba de GALLI-MAININI que emplea varias especies de renacuajos o sapos en los cuales se observa la descarga espermática.

\section{Estrógenos.}

Hay una clara evidencia de que el embarazo está asociado con una gran producción de esteroides fenantrénicos. La secuencia de su biosíntesis es, indudablemente, la misma que se opera en el ovario, la suprarrenal y el testículo. Su producción en la placenta humana está comprobada porque se han aislado estrógenos libres de la misma en altas concentraciones, asi como también se han detectado y cuantificado en la orina y sangre de la embarazada. Sus metabolitos se encuentran en cantidades progresivamente crecientes en la orina a medida que el embarazo evoluciona y disminuyen a los niveles iniciales, rápidamente, despues del parto.

Existe un especial interés creado por la excreción de ESTRIOL, cuya formación en el organismo materno está aún en duda. Aunque la placenta contiene altas cantidades de estriol, ha sido muy difícil demostrar la conversión de estradiol a estriol dentro de este tejido (115). El problema, además, se complica, entrando ya el feto en juego, en lo que se denomina la UNIDAD FETO PLACENTARIA, concepto emitido inicialmente hace cerca de 15 años por DICZFALUSY $(42,43)$, desde entonces, confirmado experimentalmente. $\mathrm{Ni}$ la placenta ni el feto son capaces de realizar en forma aislada la completa biosíntesis de esteroides y realizan esta función complementándose el uno al otro (24). Este hecho es posible por el transporte mutuo de compuestos intermedios con un suministro de elementos básicos que provienen del organismo materno. De esta manera, es posible comprender este delicado mecanismo del génesis de los esteroides representado en la figura 1. La placenta utiliza el colesterol y la pregnenolona disponibles en la circulación materna para sintetizar la progesterona; este compuesto, conjuntamente con la dehidroepiandrosterona (DHEA) materna, es convertido, hacia el final del embarazo, por la glándula suprarrenal y el hígado fetales en sulfato de dehidroespilandrosterona (DHEAS); a su paso por la placenta, el DHEAS es convertido en estradiol, estrona y estriol. En esta forma, la placenta muestra su capacidad de biosíntesis, aromatizando los andrógenos, realizando de este modo, la siguiente conversión a estrógenos (18). Algunos investigadores (139 a), han demostrado la capacidad de conversión, 
por parte de la placenta jóven, de la DHEA marcada con sustancias radioactivas, en estrona; pero esta conversión es mucho más evidente si, in vitro, se agrega tejido hepático fetal, lo cual es un argumento adicional para comprobar el papel activo del hígado fetal en este proceso metabólico. Por consiguiente, habiéndose comprobado ya el orígen de los estrógenos en la embarazada, comprendemos el porque de la utilidad de su determinación como prueba de función placentaria $(36,67)$.

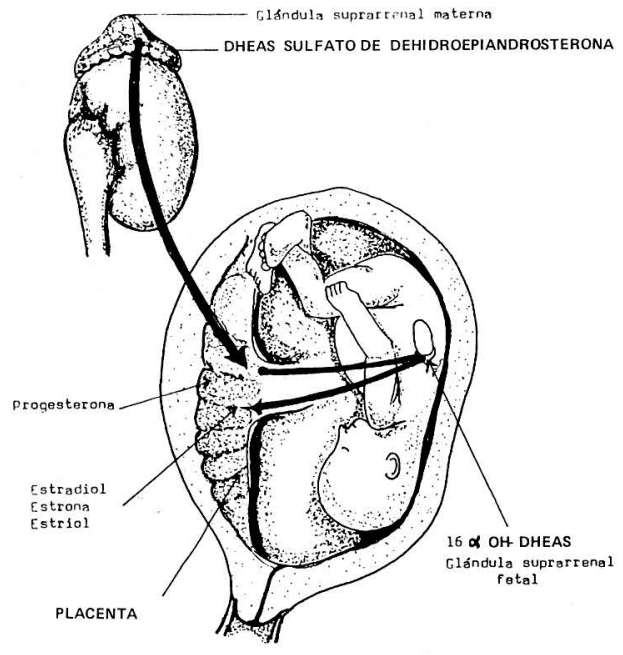

Fig. 1- Biosintesis de los

Esteroides en la Unidad

Feto Placentaria

De los estrógenos principales (estriol, estrona y estradiol), el estriol es, cuantitativamente, el más importante, pues representa por lo menos el 80 a $90 \%$ de los estrógenos urinarios de la embarazada. La concentración de estriol es 5 a 6 veces más alta en la circulación fetal que en la materna (4). Por consiguiente, la síntesis del estriol depende del feto y de la placenta; la síntesis de estradiol y estrona depende menos del feto, mientras que la de la progesterona depende exclusivamente de la placenta $(14,44)$.
La eliminación urinaria del estriol no varía con la edad o la paridad de la madre, ni con el sexo del feto; sin embargo, hay diferencias entre los grupos sociales (13).

\section{Niveles sanguíneos y urinarios.}

La sangre materna, en la últimas semanas del embarazo, contiene 1.5 a 4.6 gammas/100 c.c. de estrona, 0.7 a 1.4 gammas/ 100 c.c. de estradiol y 5.2 a 8.0 gammas/ 100 c.c. de Estriol (113); Brown (21), ha encontrado que la producción diaria de estrógenos se eleva desde $1 \mathrm{Mg}$. a la $10 \mathrm{a}$. semana del embarazo hasta $100 \mathrm{mg}$. diarios cerca al término. En contraste, durante el ciclo mestrual, se producen cantidades muy pequeñas de estrógenos, variando desde 0.08 a $0.34 \mathrm{mg}$. diarios, con una cantidad total que no excede de $4.8 \mathrm{Mg}$. durante todo un ciclo de 30 días.

No hay duda de que la producción de estrógenos durante las primeras cinco semanas del embarazo proviene predominantemente del cuerpo lúteo. La ooforectomía bilateral previa a la sexta semana del embarazo, está asociada con disminución de la excreción urinaria de estrógeno; sin embargo, si esta intervención se realiza posteriormente a esta fecha del embarazo, no ocurre cambio en los niveles estrogénicos. $\mathrm{Ha}$ cia la séptima semana, los niveles urinarios se elevan en forma brusca (21), lo que indica que en esta época la fuente principal radica en la placenta. Por medios histoquímicos se ha demostrado que el sitio de producción de estrógenos es el sincitiotrofoblasto (139).

Antes de la séptima semana los niveles ascienden lentamente hasta el ascenso brusco ya mencionado. Después sigue la excreción en forma de una curva ascendente y suave que se aplana hacia el fin del embarazo (gráfica $1 \mathrm{~B}$ ). Por consiguiente, hacia la semana 40 , los niveles tanto de estrona como de estradiol son, aproximadamente, cien veces mayores que los que se encuentran en la fase luteal del ciclo mestrual. Por otra parte, los niveles de estriol hacia el término del embarazo, son mil veces más altos que los hallados en la misma época del ciclo. Los valores de los tres esteroides al comienzo del trabajo, son similares a los anteriores, comprobándose el hecho de que no 
existe correlación entre la excreción de estrógenos y el desencadenamiento del trabajo. Después del parto, hay un rápido descenso de los niveles urinarios.

\section{Aplicaciones clínicas.}

Es generalmente aceptado que las determinaciones del estriol urinario son más útiles, clínicamente, que las del pregnandiol, estrona o estradiol y están dirigidas a valorar el ambiente fetal y, por ende, el desarrollo y peso del feto.

Durante el embarazo normal, los niveles urinarios de estriol ascienden desde 3 a 6 mg./24 horas a la 20 a. semana del embarazo hasta 5 o 6 veces más a la $40 \mathrm{a}$. semana aunque los valores obtenidos pueden depender del método analítico empleado (24). En términos generales, las cifras inferiores a las ya mencionadas suelen acompañarse de peso fetal bajo al nacimiento (75, 141). Una disminución a la mitad de los valores normales, es una señal de retardo en el desarrollo fetal o de entidades que conducen a la toxemia severa. Niveles bajos de estriol cerca al término del embarazo, pueden indicar la muerte inminente del feto in utero, aunque hay diversas opiniones sobre estos valores. Los niveles que oscilan entre 1 y $12 \mathrm{mg} . / 24$ horas han sido la guía empleada para este diagnóstico; tal vez, la cifra de $4 \mathrm{mg} / 24$ horas es la más aceptada. Una disminución brusca en la excreción de estriol puede ser indicación de la necesidad de interrumpir un embarazo prolongado. Por otra parte, DUHRING (49) establece la siguiente pauta sobre la excreción urinaria de estriol en la madre: con cifras superiores a $12 \mathrm{mg} . / 24$ horas después de la 34a. semana la mortalidad fetal o neonatal es rara; entre 4 y 12 mg. $/ 24$ horas en el embarazo a término, no se producirá parto de feto muerto, pero pueden esperarse algunas dificultades y también un pequeño porcentaje de muerte neonatal; con hallazgos inferiores a $4 \mathrm{mg}$. $/ 24$ horas, la muerte intrauterina es una posibilidad alarmante y los fetos nacidos vivos tendrán un gran índice de complicaciones en el post-parto. BEISCHER y colaboradores (13), han comprobado que la mayor parte de complicaciones fetales durante el parto, en ausencia de toda anomalía clínica, pueden prevenirse con determinaciones urinarias de estriol. Se ha observado que los lactantes que sobreviven a pesar de una eliminación baja de estriol materno y de complicaciones durante el parto, muestran una frecuencia elevada de problemas cerebrales ulteriores (136).

El valor diagnóstico del estriol urinario es disminuído por las extremas variaciones diarias, aún en la madre con embarazo único; por consiguiente, las determinaciones seriadas son necesarias para obtener el patrón completo de excreción. Aún así, es necesario recurrir a otros indicadores del estado fetal y no confiar aisladamente en las determinaciones del estriol. La medición de esteroides producidos solamente por el feto, que no sufran metabolismo adicional en la placenta o en el organismo materno, suministraría una información más exacta sobre el estado fetal. Un ejemplo de estos compuestos es el ESTETROL (15٪ -hidroxiestriol) producto del metabolismo del estradiol materno en el organismo fetal (138), pero su determinación en la orina materna no ha sido todavía realizada. La determinación de este elemento nos proporcionará un dato más confiable sobre el estado fetal, que la dosificación del estriol.

\section{Progesterona}

Los efectos fisiológicos de la progesterona se hacen evidentes con la presencia de los estrógenos. La progesterona es parcialmente responsable del transporte del óvulo fecundado a la cavidad uterina y de la preparación del endometrio para que el embrión, recientemente implantado, encuentre una nutrición adecuada. Complementa también la acción previa de los estrógenos sobre el lecho vascular del endometrio, promoviendo el crecimiento de las arterias espirales, aumentando así el riego sanguíneo del mismo. Igualmente, la progesterona es responsable de la formación de la decidua en la fase secretora tardía del ciclo menstrual $y$, por consiguiente, en el embarazo temprano.

El efecto de la progesterona sobre la motilidad uterina es todavía motivo de controversia, pero se sostiene que su acción estriba en la inhibición de cualquier efecto en el proceso bioquímico que compromete a los estrógenos y sus efectos estimulato- 
rios sobre la síntesis de la actomiosina y el ATP. (69).

El crecimiento de las mamas durante el embarazo está bajo la influencia tanto de los estrógenos como de la progesterona. Los estrógenos estimulan la proliferación de los conductos galactóforos y el crecimiento y pigmentación de los pezones y aréolas, mientras que la progesterona influencia el desarrollo de los acinos glandulares.

La progesterona produce un alza de la temperatura basal corporal durante la fase luteal del ciclo, fenómeno producido por un estímulo de los centros termogénicos del diencéfalo. Cuando ocurre fecundación, la temperatura permanece elevada; pero, a pesar de que la progesterona es secretada por la placenta durante todo el embarazo, la temperatura basal recupera su nivel normal hacia el día 100 de la gestación; el mecanismo de esta disociación termogénica es desconocido.

Como ya hemos dicho, el papel de la progesterona después de que el embarazo se ha establecido, establece el mantenimiento de un ambiente materno óptimo, incluyendo su acción sedante de la contractilidad miometrial y, tal vez, un control íntimo de la génesis del trabajo del parto cuyo mecanismo no está completamente dilucidado.

La evidencia de la producción de la progesterona por parte de la placenta incluye su aislamiento de las placentas humanas en todos los períodos de gestación y de las muestras obtenidas de la sangre arterial y venosa periférica, uterina y umbilical. La sangre afluente en las venas umbilical y uterina contiene niveles de progesterona más altos que la sangre afluente periférica. Igualmente, el nivel en la vena umbilical es más alto que en la arteria similar. Una comprobación adicional radica en la detección de su metabolito urinario, el pregnandiol, cuyas cantidades aumentan a medida que progresa el embarazo y desaparece despues del parto (69).

Empleando técnicas marcadas con sustancias radiactivas, BLOCH (17) demostró la conversión del colesterol en pregnandiol en el tejido placentario. Esta observación sugirió que el colesterol es un precursor de la progesterona puesto que el pregnandiol es su metabolito principal. Posteriormente se ha establecido la via principal de la síntesis de la progesterona partiendo del acetato al colesterol, a la pregnenolona y a la progesterona (gráfica 3). Además, la progesterona puede ser transformada en 17-hidróxiprogesterona en la placenta, y su metabolito, el pregnantriol, ha sido determinado en la orina en cantidades crecientes a medida que avanza el embarazo. En la última parte del mismo, la placenta produce diariamente, grandes cantidades de progesterona. Por otra parte, las cantidades secretadas, tanto por el cuerpo amarillo como por las glándulas suprarrenales, son insignificantes porque se ha demostrado experimentalmente que los niveles de pregnandiol urinario no se afectan despues de la fuoforectomía o de la adrenalectomía.

acetato

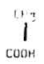

colesterol

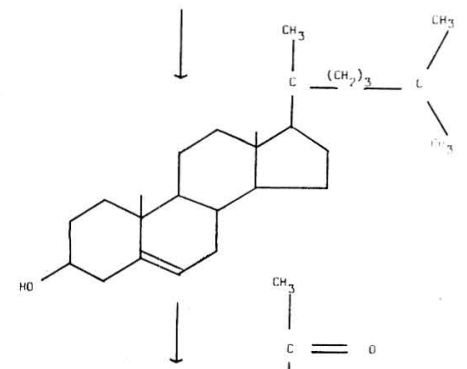

pregnenolona

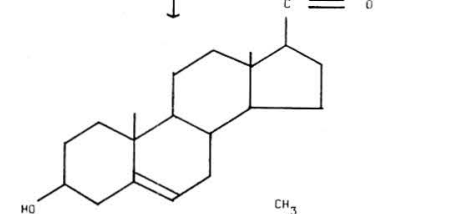

progesterona

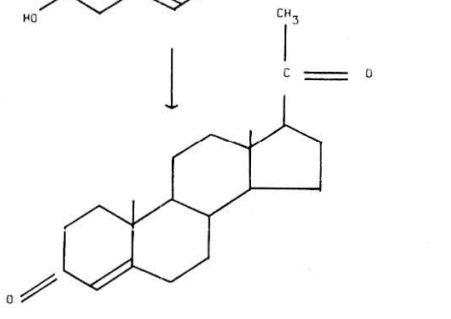

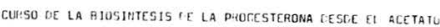

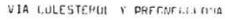

\section{Niveles sanguíneos y urinarios}

La presencia del pregnandiol en la orina se establece inmediatamente despues de la 
ovulación y continúa ascendiendo progresivamente durante el embarazo hasta la 32a. semana cuando alcanza una meseta de, aproximadamente, $80 \mathrm{mg} . / 24$ horas (39) (gráfica 4A). Es conveniente aclarar que los valores urinarios difieren según la técnica empleada. Recientemente se han registrado niveles promedios de $40 \mathrm{mg}$. en orina/24 horas después de la 32a. semana. PEARLMAN (103), empleando técnicas de isótopo-dilución registró la producción de progesterona endógena durante el último trimestre del embarazo, encontrando valores aproximados a $250 \mathrm{mg}$. diarios.

En contraste con las grandes cantidades de pregnandiol excretadas en la orina, la concentración de progesterona en el plasma sanguíneo es muy baja. ZANDER (142), encontró niveles de 0.039 a 0.268 microgramos/c.c. de plasma desde el 4o. hasta el 9o. mes de gestación. Consecuentemente, los niveles en la sangre retroplacentasria son mucho más altos. Las concentraciones en el tejido placentario son más altas du- rante el 2o. y 3er. mes que en la última época del embarazo pero el contenido total en la placenta se eleva considerablemente a medida que progresa el embarazo.

\section{Aplicaciones clínicas}

Las determinaciones de pregnandiol urinario son menos útiles de lo que se creyó originalmente. Sin embargo, algunos autores $(24,69)$ las recomiendan como signo pronóstico de la viabilidad placentaria; sus niveles, a menudo, se encuentran reducidos en la toxemia gravídica, en el retardo del desarrollo fetal o en la inmunización $\mathrm{Rh}$, pero los resultados son muy variables para propósitos diagnósticos.

\section{Hormonas de la corteza suprarrenal.}

Numerosos estudios revelan la posibilidad de que ciertos aspectos de la función suprarrenal estén aumentados durante el embarazo. El hecho de que las concentraciones sanguíneas de 17-hidroxicorticoides

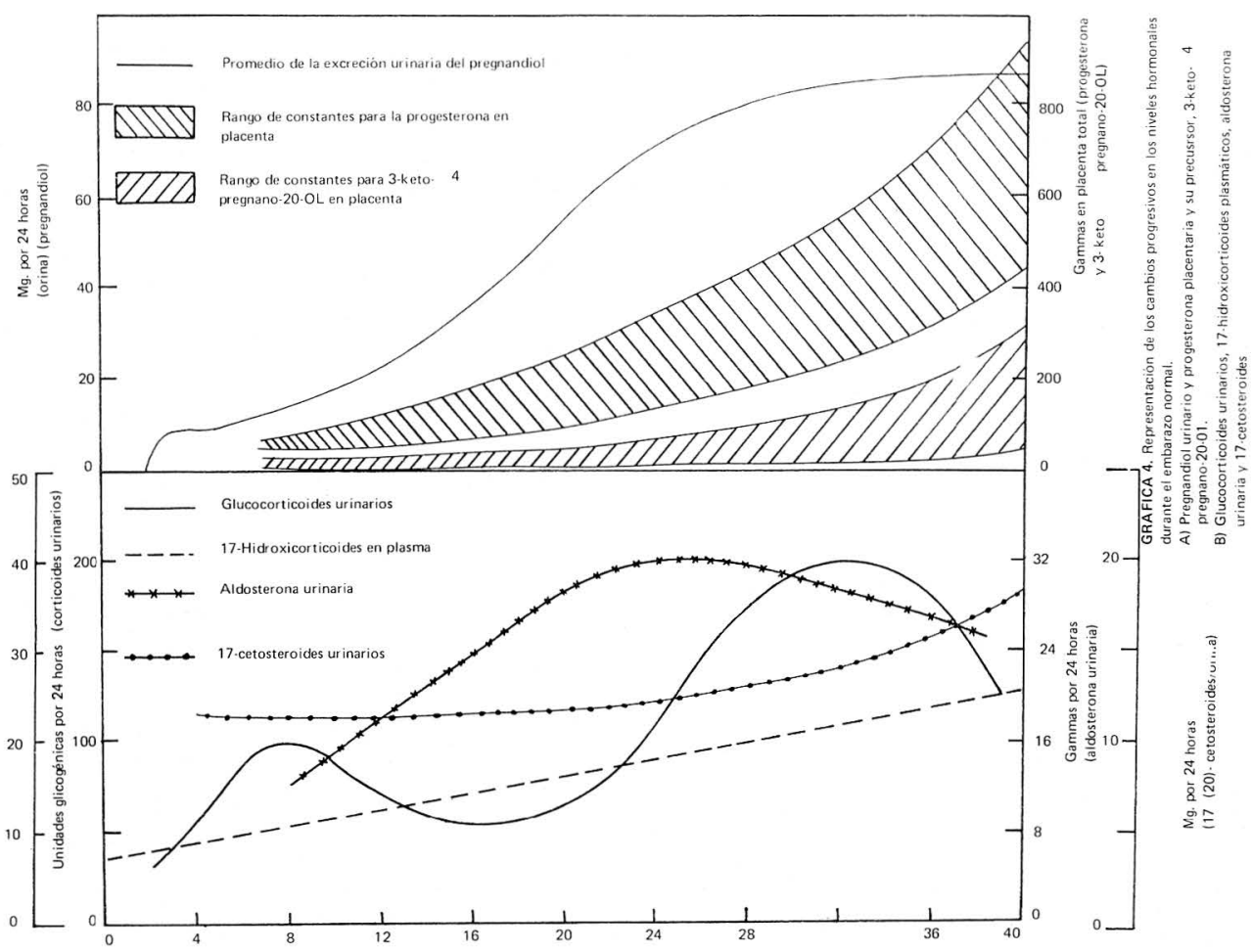


aumenten progresivamente durante el embarazo (gráfica 4-B), sugiere su posible orígen placentario. Sin embargo, este fenómeno se ha observado únicamente en embarazadas con glándulas suprarrenales sanas. En casos de embarazadas que sufren enfermedad de Addison no se ha comprobado este aumento. Además, el hallazgo de cantidades crecientes de hormonas plasmáticas parece ser debido al aumento de una proteína específica, la transcortina, la cual se liga a los corticoides; se cree que este es un efecto inducido por los estrógenos. Por otra parte, no se ha comprobado que la placenta sintetice hormona adrenocórticotropa (18).

Se ha sugerido que el aumento en los 17-hidróxicorticoides plasmáticos que se encuentra en la última parte del embarazo, puede ser el resultado de un retardo del metabolismo y destrucción así como un aumento en la velocidad de producción de hormonas corticales. Esta suposición se basa en el hecho de no existir signos clínicos de hipercorticoidismo en el embarazo a pesar de los altos niveles de esteroides corticales. Aún más, es probable que el aumento en la producción de estrógenos por parte de la placenta juegue un papel en la disminución de la velocidad de difusión del cortisol desde el torrente circulatorio hacia los tejidos corporales.

La excreción de aldosterona está aumentada en el embarazo pero este fenómeno no se encuentra en pacientes con insuficiencia córticosuprarenal, lo que hace pensar que esta hormona no es producida por el tejido placentario. Se encuentra un aumento progresivo en la excreción urinaria de aldosterona durante el embarazo normal, seguido por rápida disminución despues del parto (gráfica 4 B). La mayor cantidad de esta hormona es excretada en forma conjugada.

El papel que juega la aldosterona no está completamente dilucidado; es posible que tenga una acción sobre las alteraciones del balance de los electrolitos y agua pero esto no está confirmado y son muchos los estudios que se están realizando en la actualidad sobre las diversas funciones de esta hormona.

La determinación de los 17-Cetosteroides no muestra gran variación comparada con la mujer no embarazada. La excreción de androsterona, etiocolanolona y dehidroisoandrosterona disminuye durante el último trimestre del embarazo. Sin embargo, es en esta época en que la producción hormonal placentaria se encuentra en su más alto nivel. PLOTZ y DAVIS (105), observaron que la administración de altas dosis de progesterona en los primeros meses del embarazo produjeron una disminución en la excreción de androsterona y etiocolanolona confirmando así el concepto de que la actividad hormonal de la placenta altera la función normal de la corteza suprarrenal. Los numerosos estudios experimentales sobre este aspecto no son concluyentes sobre la posible sintesis de hormonas adrenocorticales en el tejido placentario, o si este último órgano es, simplemente, un sitio de depósito de tales compuestos.

\section{Andrógenos.}

Experiencias basadas en técnicas biológicas empleando extractos placentarios, han mostrado que este tejido contiene sustancias androgénicas. Este hallazgo no es sorprendente conociendo ya el hecho de que la biosíntesis de los estrógenos se realiza por transformación de sus precursores, los andrógenos. No se han identificado en la placenta esteroides específicos C-19 tales como la testosterona. Sin embargo, SALHANICK (117), ha registrado la presencia de androstenediona.

Realmente es muy poco lo que se conoce acerca de la secreción de andrógenos durante el embarazo normal. Como ya hemos mencionado, no se han registrado cambios en la excreción urinaria de sus matabolitos, los 17-Cetosteroides (gráfica $4 \mathrm{~B}$ ). La androsterona y la etiocolanolona son excretadas en cantidades normales durante los primeros meses del embarazo, aunque se ha observado que existe una disminución en su excreción a medida que el embarazo llega a término. Igualmente, los niveles san guíneos de la dehidroisoandrosterona descienden en los últimos meses. Se cree que estos esteroides urinarios se originan de precursores elaborados por la corteza suprarrenal materna y, posiblemente también, por la suprarrenales fetales. No existe evidencia de que la placenta sea la fuente principal de los andrógenos pero la andros- 


\section{g) Catecolaminas: Serotonina}

ZUSPAN (144) ha encontrado que la producción de catecolaminas está aumentada durante la gestación. Igualmente, se ha revelado aumento en los niveles de serotonina (133). El significado fisiológico de la serotonina no está completamente aclarado pero parece existir una relación con ciertas anormalidades asociadas con la toxemia gravídica.

\section{Tiroides}

La existencia de una hiperplasia tiroidea durante el embarazo está sustentada por los hallazgos anatómicos y por los datos funcionales de laboratorio.

Se ha encontrado que el tiroides experimenta un aumento del $65 \%$ en volúmen y peso, que comienza desde el embarazo temprano. La glándula también se torna hiperhémica, sus elementos histológicos sufren hiperplasia y el coloide es reabsorbido. Respecto a las pruebas diagnósticas, se han observado los siguientes cambios: el estudio del metabolismo basal, como es bien aceptado ya, tiene muy escaso valor en el diagnóstico de la hiperfunción tiroidea y aún es menos útil durante el embarazo a causa del aumento de metabolismo. La determinación de la yodoproteinemia (PBI) es mucho más confiable y muestra cifras aumentadas al igual que los niveles de proteína unida a la tiroxina (TBP) (18). Tambien se ha informado aumento en los valores de la captación del iodo radioactivo (I131) (48, $76,109)$, y de la tiroxina plasmática $(64$, 128).

La más problable causa de esta hiperfunción tiroidea es el aumento de la actividad de la TSH durante el embarazo. Parece que en este fenómeno no interviene la HCG puesto que se ha comprobado que en casos de corioepitelioma, no se encuentra aumento de la actividad tiroidiana (48). Se podría pensar que estados hipertiroidianos como la enfermedad de Basedow, se agravarían con el embarazo; pero, paradójicamente, ocurre todo lo contrario; auncuando las pruebas de función tiroidiana se encuentran notoriamente elevadas, la embarazada no exhibe signos clínicos de hipertiroidismo (temblor, palpitaciones, nerviosidad, exolftalmus, etc.) y tolera cantidades más altas de tiroxina que la no embarazada. Por consiguiente, se sostiene que el hipertiroidismo gravídico es de naturaleza compensatoria, cuyo papel estriba en satisfacer los requerimientos crecientes de hormona tiroidea para el metabolismo, no solo materno, sino tambien fetal. Debemos recordar que la tiroxina es un agente morfogenético que acelera la metamorfosis tisular y, aparentemente, tambiés es necesaria para el óptimo desarrollo embrionario (18).

\section{Paratiroides}

Durante el embarazo, las glándulas paratiroides aumentan en tamaño, fenómeno que se atribuye a los requerimientos de calcio necesario para el crecimiento fetal. Los niveles de calcio sérico disminuyen considerablemente (135), permaneciendo los niveles de fósforo dentro de límites normales.

\section{Páncreas}

Numerosos estudios confirman el hecho de que el embarazo está asociado con una tendencia hacia el desarrollo de diabetes mellitus. En muchas mujeres, una diabetes latente se manifiesta por primera vez durante el embarazo. Por otra parte, los embarazos múltiples parecen predisponer a la diabetes pancreática. Estos hallazgos y la relativa frecuencia de la aparición de glicosuria gravídica hacen pensar con bastante fundamento en la existencia de una insuficiencia pancreática durante el embarazo. Es ta falla se puede manifestar, según algunos autores, (23), por un signo caracterizado por hiperlactacidemia. Sin embargo, otros investigadores (8.89) han hallado hiperplasia de los islotes en el embarazo. Por medio de análisis radio-inmunológico se ha encontrado insulinemia elevada durante la gestación (131), y se cree que este hallazgo es un efecto inducido por la progesterona (82). Finalmente, se afirma que el consumo normal de la insulina endógena se duplica durante el embarazo. Así, el páncreas también realiza una función compensatoria durante la gestación.

\section{Suprarrenal.}

Al tratar el aspecto de la fisiología placentaria mencionamos que existía una hiperfunción de la corteza suprarrenal du- 
rante el embarazo. La corteza aumenta en tamaño e histológicamente, se aprecia hiperplasia, particularmente de la zona fasciculada. Por el contrario, la zona reticular está notoriamente disminuída en espesor.

No debemos olvidar que la suprarrenal es una fuente adicional de progesterona gravídica y constituye una especie de "puente" entre la fase luteal del ovario y la fase de la síntesis de progesterona placentaria. Sin embargo, sería muy raro que ocurriera síntesis de los esteriodes sexuales en ausencia de hiperplasia de la zona sexual, como se denomina también la zona reticulada. Actualmente, es bien reconocido que de todos los esteroides sexuales comprometidos en el metabolismo cortical, la progesterona es el único que se origina en la zona fasciculada. La presencia de hiperplasia de esta zona, sin compromiso de la reticular, sería por consiguiente, el patrón esperado en el embarazo.

Los niveles plasmáticos de glucocorticoides $(63,109)$ y de la mineralocorticoides $(47,107)$ se encuentran elevados durante la gestación (gráfica $4 \mathrm{~B}$ ). Igualmente, se ha demostrado la existencia de altos títulos de transcortina $(47,112)$. Los anteriores hallazgos permiten concluir que durante la gestación existe una hiperfunción compensatoria de la corteza suprarrenal para responder a la aumentada demanda de corticoides.

\section{SISTEMA ENDOCRINO FETAL}

Al comienzo de la vida embrionaria, las glándulas endocrinas del feto se encuentran en estado inmaduro y por lo tanto, no poseen función alguna. Hacia la mitad de la gestación algunas de ellas comienzan a mostrar una leve actividad la cual se va haciendo más evidente a medida que el feto alcanza su término. Revisemos someramente estos aspectos endocrino-fetales.

\section{Gonadas.}

Las gonadas fetales muestran un cierto grado de actividad esteroidogénica. Sin embargo este fenómeno es bastante diferente según el tejido gonadal. Así, mientras el comportamiento endocrino del ovario es débil, el del testículo exhibe una actividad precoz interviniendo en el proceso de la di- ferenciación sexual, según lo ha demostrado JOST $(80,81)$.

El comienzo de la esteroidogénesis en la gonada embrionaria se manifiesta por la aparición de una enzima denominada 3 -o1dehidrogenasa la cual ha sido detectada en forma temprana, antes de llegar hacia la mitad del embarazo, en el tésticulo fetal. En cambio su búsqueda en el ovario fetal ha sido negativa, en la misma época de la gestación.

Hay muchas controversias acerca del factor que produce el estímulo hormonal sobre las gonadas fetales. Se cree que puede ser la gonadotropina coriónica; pero se supone también que la acción se realiza mediante la hipófisis fetal, pero realmente no existen investigaciones concluyentes sobre este tópico. Por otra parte, existen muchos estudios que sostienen la biogénesis esteroide en el organismo fetal y que compromete a estrógenos, andrógenos y progesterona; pero esta función no puede ser adscrita exclusivamente a las gonadas fetales puesto que este fenómeno es, principalmente, el producto de un intercambio entre la suprarrenal fetal y la placenta, con alguna participación del hígado, como ha sido demostrado por DICZFALUSY (45).

\section{Suprarrenal.}

La actividad endocrina de la corteza suprarrenal es una de las más importantes durante la vida intrauterina; se desarrolla, llegando también a un máximo de función, alrededor del 4o. mes de la gestación.

Antes del 7 o. mes, la corteza está compuesta casi exclusivamente de zona reticular y solamente después de este término comienza el desarrollo de las zonas fasciculada y glomerular (18) Por consiguiente, existen dos componentes funcionalmente diferentes: el primero denominado suprarrenal sexual, está comprometido con el metabolismo de los esteroides propios, esto es, estrógenos y andrógenos; el segundo, designado como suprarrenal metabólica, está relacionado con la síntesis de los corticoides. Al nacimiento, la zona sexual se atrofia dando lugar al fenómeno conocido como atrofia post-natal de la glándula, proliferando en cambio la suprarrenal metabólica, persistiendo como la glándula exclusiva en la infancia. Por lo anteriormente 
mencionado se concluye que no hay producción de corticoides fetales sino hasta después del 7o. mes de gestación. Hay alguna especulación acerca del papel que juega el ACTH materno, que como hemos visto está aumentando durante el embarazo, en el desarrollo de la función corticoidogénica de la suprarrenal fetal. Otra posibilidad estriba en el hecho de que esta glándula, eventualmente, alcanza su madurez capacitándola para la síntesis de corticoides ya en el momento del nacimiento.

\section{Tiroides.}

El tiroides fetal muestra signos de actividad en una época bastante temparana. Algunos investigadores (127) han encontrado captación positiva de I 131 hacia la 12 a. semana del embarazo. Otros (102) han informado que la síntesis de tiroglobulina por el tiroides fetal comienza alrededor del día 56o. de la gestación.

La relación entre esta indudable actividad del tiroides fetal y el compartimento materno no ha sido suficientemente aclarada. Hay dudas acerca de cual puede ser el factor que activa el tiroides en el medio amniótico. Algunos sostienen que puede ocurrir paso de tiroxina de la madre al feto, en el que ejercería el papel regulador del sistema hipotálamo-hipofisario; otros afirman que existe paso de tirotropina materna al compartimento fetal; pero en el presente, no hay consenso acerca de cual puede ser el mecanismo endocrino definitivo sore este aspecto.

\section{Páncreas.}

Estudios en animales pancreatectomizados han mostrado que la diabetes experimental es mucho menos severa si el animal está gestando. Además, la pancreatectomía al comienzo de la preñez producía efectos mucho $\mathrm{m}$-as graves que si se realizaba en un estadio tardío de la gestación. Durante la misma, el animal permanecía en un estado más o menos compensado pero desarrollaba una típica diabetes después del parto. Estos hallazgos sugieren que por la época en que se desarrolla el páncreas fetal, secreta suficiente insulina que atraviesa la barrera placentaría y protege a la madre de los efectos adversos de la extirpación del páncreas.
En el feto humano se ha encontrado que el páncreas es funcionalmente activo hacia el final del 3er. mes de gestación. Los islotes de Langerhans son numerosos y su contenido de insulina es alto, con valores más elevados que los encontrados en el adulto (106). Los valores de la glicemia relativamente bajos, encontrados usualmente en el recien nacido, podrían indicar un estado hiperfuncional del páncreas. Sin embargo, al alto contenido de glicógeno hepático sugeriría una aceleración en el almacenamiento, más bien que utilización.

\section{Hipófisis.}

La pituitaria fetal está morfológicamente desarrollada hacia el final del primer trimestre, pero es funcionalmente inactiva durante toda la gestación. Aún más, la hipófisis al nacimiento no responde al estímulo hipotálamico. Aparentemente, este fenómeno es el resultado, no de la ausencia de la actividad endocrina de la hipófisis, sino de la falta de maduración del sistema nervioso; y este mecanismo rige también para la vida embrionaria. CORNBLATH y colaboradores (27) han demostrado que la hormona del crecimiento es producida por la pituitaria fetal, y este hallazgo favorece el concepto de una posible actividad independiente de esta glándula durante la vida intrauterina.

\section{Paratiroides.}

Las glándulas paratiroides del feto a término realizan una función activa y están listas para asumir la muy importante tarea de regular el metabolismo del calcio en el nal compensatoria y recíproca entre la paratiroides fetal y la materna, muy semejante a lo que ocurre, según ya hemos descrito, con el tiroides, suprarrenal y páncreas. $(3,137)$.

Se ha descrito un sindrome bastante interesante consistente en hiperparatiroidismo materno asociado a tetania en el recién nacido $(132,137)$. Este es un excelente ejemplo de como la actividad funcional excesiva de una de las glándulas maternas puede producir atrofia de la glándula fetal homóloga y viceversa. 


\section{Timo.}

El desarrollo del timo es uno de los fenómenos más interesantes de la endocrinología fetal. Aunque su completa función es aún escasamente conocida, no hay duda de que el timo es un antagonista de la gonada durante el desarrollo embrionario. La ausencia del timo en fetos masculinos, a diferencia de los femeninos, está asociada con elevada mortalidad fetal, como si la causa subyacente produjera una intolerancia al efecto de los estrógenos (73). BEARN (11), hace hincapié en el efecto antagonista ejercido sobre el timo por la suprarrenal y por la hipófisis. La anencefalia está asociada con hiperplasia del timo y al mismo tiempo con aplasia de la hipófisis y de la suprarrenal $(51,121)$. No sobra mencionar la enorme importancia del timo en la génesis de todo el sistema linfoide de la economía y es allí donde se generan los primeros linfocitos que aparecen en el feto (72).

\section{FISIOLOGIA ENDOCRINA DEL PARTO.}

\section{Períodos del parto.}

El parto propiamente dicho se divide en tres períodos que son los siguientes:

a) Primer período: desde el comienzo de las contracciones uterinas regulares hasta la dilatación completa del cérvix, que se incorpora así a la vagina para formar el canal blando del parto. Duración: primigrávidas, aproximadamente 10 a 12 horas; multíparas, aproxintadamente 6 a 8 horas.

b) Segundo período: desde la dilatación completa del cérvix hasta la expulsión del feto. Durante este período, las fuerte contracciones uterinas están acompañadas por un aumento de la presión intra-abdominal producida por la actividad de la musculatura voluntaria de la pared abdominal.

Duración: primigrávidas, aproximadamente 1-1/2 horas; multíparas, aproximadamente 15 a 30 minutos.

c) Tercer período: desde la expulsión del feto hasta el alumbramiento (expulsión de placenta y sus membranas).

Duración: aproximadamente 15 a 30 minutos.

\section{Mecanismos desencadenantes del parto.}

Existen algunos mecanismos maternos y fetales que pueden influenciar el comienzo del trabajo del parto. Una gran variedad de factores influencian la actividad contráctil del útero pero no hay acuerdo sobre su relativa importancia en determinar el momento del comienzo del trabajo. Los mecanismos desencadenantes son distintos según las especies, entre los individuos de una especie y en ocasiones sucesivas en el mismo individuo. Algunos autores creen que existe un mecanismo particular, definitivo; otros hacen hincapié en la importancia de un balance entre los factores con efecto opuesto sobre la contractilidad uterina, por ejemplo, progesterona y volumen uterino (30, 31), progesterona y estrógenos, progesterona y cortisol (115a), o progesterona y prostaglandinas (32). Cualquiera que sea el factor desencadenante, cuando el parto comienza bajo condiciones normales, parece desarrollarse "una cascada de fenómenos" en la cual un número de mecanismos de retroalimentación positivos, por ejemplo, el "reflejo de salida del feto", la suspensión de la progesterona por la separación placentaria, reflejos medulares, la tensión inducida por la liberación de prostaglandinas, etc., actuan en conjunto para mantener y llevar a cabo el proceso del parto hasta su terminación. Revisemos brevemente estos mecanismos.

\section{a) Inervación motora autónoma.}

La inervación autónoma del útero puede influenciar su actividad contráctil tanto por la vía simpático-adrenérgica como por la parasimpático-colinérgica. La inervación excitable colinérgica del útero humano no grávido está aparentemente bloqueada durante el embarazo (99). Los estrógenos pueden estimular la contractilidad uterina por aumento de la síntesis y captación de catecolaminas en el miometrio; una disminución en los niveles de progesterona podrían reducir la acción beta inhibitoria de los nervios adrenérgicos y aumentar sus efectos alfa estimulantes (123). El suministro nervioso adrenérgico al útero puede constituir la rama eferente de un arco reflejo medular con lo cual las contracciones uterinas son estimuladas por la dilatación cervical (116); además, la inervación adrenérgica puede aumentar la sensibilidad del 
miometrio a la ocitocina (114). La inervación uterina puede influenciar su riego sanguíneo (70), diciéndose que una disminución en su irrigación puede, talvez, desencadenar el comienzo del trabajo del parto $(\mathbf{2 0})$.

Los niveles sanguíneos de catecolaminas de la mujer en trabajo, no son diferentes de los encontrados en la mujer no embarazada (77). No obstante, el útero denervado experimentalmente en animales, aún funciona en condiciones relativamente normales durante el parto y en el humano se ha observado que el parto se desarrolla normalmente a pesar de lesiones que produzcan una sección completa de la medula espinal (94).

\section{b) Estrógenos.}

Como lo hemos mencionado anteriormente, los estrógenos son un grupo de hormonas esteroides que poseen actividades biológicas similares. El estriol es, cuantitativamente, el estrógeno más importante durante el embarazo y, como ya hechos dicho, es sintetizado conjuntamente por el feto y la placenta. Las embarazadas cuyos fetos sufren de atrofia suprarrenal, secretan niveles bajos de estrógenos (60); por otra parte, estos compuestos alcanzan su pico máximo de excreción cuando comienza el parto (12).

Los estrógenos pueden influenciar la contractilidad uterina por una acción directa sobre el miometrio o indirectamente, aumentando la liberación de ocitocina de la glándula pituitaria (108), o de las prostaglandinas provenientes del útero (16). La administración de estradiol a la mujer embarazada precipita el comienzo del parto (104).

\section{c) Ambiente externo.}

Las observaciones hechas en mamiferos han mostrado que el parto se desarrolla generalmente en un ambiente tranquilo; es común que el animal se separe del rebaño y escoja un lugar oscuro y sosegado. El efecto inhibitorio del "stress" sobre la liberación de ocitocina puede ser reducido al mínimo por este patrón de conducta. Por otra parte, estímulos desagradables y violentos pueden provocar una respuesta uterina rápida y precipitar el parto. Se ha observado que mamíferos inferiores como en las ratas, un ambiente estraño influencia el comienzo y duración del parto con aumento en la mortalidad en las crías (100). En los seres humanos, la mayoría de los partos ocurren durante la noche con una mayor frecuencia hacia las 3 a.m.. Se ha observado también que factores tóxicos como el tabaco alteran la duración del embarazo; asi por ejemplo, éste está acortado de 29 a 34 horas en mujeres que fuman regularmente comparado con el de las que no fuman (22).

\section{d) "Stress" fetal, ACTH y Corticosteroides.}

Este es uno de los aspectos más interesantes por las observaciones que se han hecho tanto en animales como en humanos. Se ha comprobado que el feto puede influenciar la duración del embarazo. El ejemplo más evidente se ha visto en hibridos del caballo y del burro. La duración promedio del embarazo de una yegua preñada por un caballo es de 340 días, pero si es preñada por un burro es de 355 días (53).

El eje hipotálamo-hipófiso-suprarrenal del feto ovino influencia la duración del embarazo. La preñez es prolongada por varias semanas en la oveja intoxicada con la semilla de "veratrum californicum" la cual produce una deformidad del cráneo fetal con ausencia de la glándula pituitaria (15).

La destrucción experimental de la hipófisis o del hipotálamo fetal produce gestación prolongada. Varios días antes del parto se encuentra un alza de los niveles de los corticosteroides fetales sin correlación con los niveles maternos (10), y está probablemente asociada con un aumento de la actividad de la 11 hidroxilasa de la suprarrenal fetal. La actividad de esta enzima está aumentada por la ACTH la cual es probablemente liberada en cantidades crecientes por la hipófisis fetal hacia el fin de la gestación. E1 estímulo secretorio del ACTH fetal está iniciado probablemente por el "stress" (6). El estímulo de la corteza suprarrenal por medio de infusión de ACTH (91), o de cortisol (92) intrafetal produce un parto prematuro.

En el humano también, la hipótisis y la corteza suprarrenal fetales pueden influenciar la iniciación del parto. La anencefalia 
asociada con hipoplasia suprarrenal está acompañada por prolongación del embarazo (97). Inversamente, se ha observado que el parto prematuro puede estar asociado con un aumento inusitado del peso de la suprarrenal fetal (9). En caso de muerte fetal, la madre comienza el trabajo aproximadamente una semana despues del deceso (31). La función endocrina fetal no es, por consiguiente, vital para la iniciación del trabajo aunque el feto tiene influencia sobre el momento del parto en una forma todavía imperfectamente definida.

\section{e) Estimulación mecánica.}

La estimulación mecánica del útero, por ejemplo, por el volúmen de su contenido influencia el momento del parto. El incremento del volumen uterino eleva la actividad contráctil del miometrio y en caso de encontrarse un volumen uterino anormalmente aumentado, por ejemplo, en el embarazo gemelar o en el polihidramnios, se precipita un trabajo prematuro $(30,31)$.

Se puede inducir el parto o el aborto por medio de la ruptura artificial de las membranas (decidua endometrial y corion fetal) ya sea por amniotomía o por la inyección intraovular de líquidos. Estos procedimientos pueden estimular la liberación de prostaglandinas provenientes del tejido decidual.

La estimulación mecánica del cérvix y la vagina aumenta las contracciones uterinas posiblemente debido a un mecanismo miogénico directo o a un reflejo medular (29, 57). Los receptores mecánicos en el útero (2) también estimulan el hipotálamo por vía medular (1) produciendo un aumento de la actividad de las neuronas en el núcleo paraventricular que controla la liberación de ocitocina de la hipófisis posterior (19). La interrupción de estas vías puede detener el parto en mamíferos inferiores, pero por otra parte, como ya hemos mencionado, en la mujer no se altera el trabajo a pesar de lesiones transversas completas de la medula espinal (94).

\section{f) Ocitocina.}

La ocitocina (en griego, "nacimiento rápido") es una hormona octapép tido que estimula la actividad contráctil del miome- trio. La ocitocina circulante liberada por la hipófisis materna, es uno de los factores importantes en la iniciación y mantenimiento del trabajo normal y su forma sintética es empleada en la inducción terapéutica del trabajo. La sensibilidad del miometrio a la ocitocina es aumentada por los estrógenos y disminuída por la progesterona (95). Durante el parto, el estímulo que provoca la liberación de ocitocina surge primariamente del estímulo mecánico del útero, el cérvix y la vagina $(25,52)$. Este "reflejo de expulsión fetal " es rápidamente inhibido por el "stress" (100). El hallazgo de que la ocitocina liberada por medio de la succión es inhibida por el etanol, condujo al empleo exitoso del alcohol en el tratamiento de la amenaza del parto prematuro en la mujer (143); el alcohol también inhibe directamente la respuesta endometrial a la ocitocina y a las prostaglandinas (86). Se sostiene que durante el trabajo, los niveles de ocitocina en sangre materna son bajos durante el primer período y más altos durante el segundo período del parto (25).

También se afirma que el feto puede liberar ocitocina durante el trabajo (35). Por otra parte, se ha demostrado que la ocitocinasa, una enzima que se encuentra en el torrente circulatorio de la embarazada y que degrada la ocitocina, no tiene importancia alguna en la iniciación del parto ya que su actividad permanece constante antes, durante y después del trabajo (134).

\section{g) Progesterona.}

La progesterona es necesaria para el mantenimiento del embarazo en mamíferos. Es sintetizada por la placenta a partir del colesterol materno. No existe una disminución significante de los' niveles de progesterona plasmática antes del parto espontáneo, pero sí se aprecia una caída notable después del alumbramiento $(93,140)$. La concentración de progesterona plasmática varía notablemente en la misma mujer a diferentes horas del día y durante los diferentes días en la etapa final del embarazo (28). La placenta es la principal fuente de producción de progesterona, la cual ejerce un bloqueo de la actividad del miometrio y existe controversia sobre una reducción de este 
bloqueo como factor desencadenante del parto.

\section{h) Prostaglandinas.}

Como hemos mencionado anteriormente, las prostaglandinas son un grupo de compuestos químicamente relacionados con los ácidos grasos y se encuentran ampliamente distribuídos en los tejidos. El líquido amniótico obtenido durante el trabajo contiene altas concentraciones de prostaglandina $(\mathrm{PG}) \mathrm{F}_{2} \propto$, que estimula las contracciones uterinas; el líquido amniótico obtenido durante el embarazo contiene solamente pequeñas cantidades de otra prostaglandina denominada $P G E_{1}$ y no se detecta la $P G$ $F_{2} \propto$. Estos compuestos no se han detectado en la circulación materna antes del trabajo del parto (84), pero durante el parto se ha encontrado en la sangre venosa la PG $\mathrm{F}_{2} \propto y$ se ha sugerido que estos elementos son sintetizados por la decidua (85).

Desde el punto de vista terapéutico se han empleado la $P G \quad E_{2}$ y la $P G F_{2} \propto$ por vías endovenosa, oral, intravaginal e intraamniótica para inducir el trabajo, sosteniéndose que se estimula así un mecanismo que libera la ocitocina.

\section{FISIOLOGIA ENDOCRINA DEL PUERPERIO}

Mencionamos atrás que el trabajo concluye con la terminación del tercer período del parto. Después de la expulsión de la placenta, comienza el estado puerperal y la paciente es considerada como puérpera. Por consiguiente, el puerperio comienza después del parto del niño, de la placenta y las membranas ovulares y termina cuando los órganos genitales externos e internos maternos retornan a su estado previo al embarazo. Tiene una duración de 6 a 8 semanas. Por lo tanto, el puerperio está caracterizado por cambio regresivos o involutivos de los órganos reproductivos de la madre y por cambios progresivos mamarios que capacitan al seno para su función de nutrición del niño y que consideraremos en el siguiente aparte.

En el aspecto endocrino, tal vez, el factor más importante durante esta época, es el retorno de la menstruación y ovulación. La reaparición de la menstruación es bas- tante variable. La lactancia tiende a demorar su comienzo. Generalmente se acepta que la menstruación comienza alrededor de la sexta semana del postpartum. Sin embargo, SHARMAN (124) ha demostrado que ésto ocurre solamente en el $24.7 \%$; dentro de las 12 semanas en el $61.1 \%$; dentro de las 24 semanas en el $77.7 \%$. A las 12 semanas, cerca de una tercera parte de primíparas lactantes estaban menstruando en comparación a $91 \%$ de primíparas no lactantes. Una vez reestablecida, la menstruación fué regular en el $72.5 \%$ de mujeres lactantes y en el $92.2 \%$ de las no lactantes.

Basado en la evidencia obtenida por biopsias endometriales, SHARMAN (125) no pudo demostrar ovulación durante las primeras seis semanas; durante la seis siguientes, $56 \%$ de las biopsias mostraron ovulación y durante las 12 semanas siguientes, $86 \%$ ovularon. Alrededor del $42 \%$ de las primeras menstruaciones habían sido precedidas por ovulación. Una vez que la mujer ovulaba, sus ciclos subsiguientes tendían a ser ovulatorios.

Exjste una creencia bastante difundida que sostiene que la lactancia impide el embarazo. ROBINSON (111) hizo un estudio en madres que concibieron durante la lactancia y que todavía no habían menstruado. Ellas no se dieron cuenta del embarazo sobreimpuesto hasta que experimentaron los movimientos fetales. Por esta época, el feto tenía una edad de 18 a 20 semanas y el último niño había nacido 7 meses antes. Esta observación indica que la ovulación y la concepción pueden ocurrir durante la lactancia y en la práctica esto ocurre con relativa frecuencia. Por otra parte, la lactancia es bastante adecuada e inocua para el niño en presencia de un nuevo embarazo.

\section{FISIOLOGIA ENDOCRINA DE LA LACTANCIA.}

\section{Lactogénesis.}

Se denomina lactogénesis la iniciación de una descarga copiosa de leche después del parto. El alvéolo secreta calostro en forma escasa, al comienzo del embarazo y en forma más abundante durante el último trimestre, pero la secreción láctea abundante comienza 3 a 4 días después del parto. La iniciación de la lactancia está coor- 
dinada con el parto en varias formas que describiremos a continuación (55):

\section{a) Hormonas hipofisarias.}

Experimentalmente se han identificado las hormonas necesarias para la lactancia adecuada, comprobando la reducción de los niveles de las hormonas endógenas por medio de la hipofisectomía. Por consiguiente, en la mayoría de las especies, la lactogénesis es la respuesta de una glándula mamaria desarrollada, a un complejo hormonal lactogénico que comprende prolactina, ACTH, córticosteroides y tiroxina (38). La mayor evidencia favorece a la prolactina como responsable de la función lactogénica. En etapa cercana al parto, existe un descenso de los niveles de progesterona plasmática y un ascenso de los niveles estrogénicos aumentando de esta manera la formación de hormonas de la hipófisis anterior, incluyendo la prolactina $(7,71,96)$.

\section{b) Prolactina.}

Existen notables similitudes en la estructura química de la prolactina, la hormona del crecimiento y el lactógeno placentario y hasta hace sólo 4 años (120) se obtuvo una clara demostración de que la hormona del crecimiento es un compuesto diferente de la prolactina humana. Es mucho lo que se desconoce de esta última hormona; por ejemplo, la relación entre la secreción de prolactina y los esteroides ováricos es compleja. Estudios in vitro han demostrado resultados evidentes de que el estradiol estimula la secreción de prolactina. También se ha comprobado que, por lo menos en algunas especies, la prolactina tiene actividad luteotrópica. En cuanto al efecto sobre la mama, el circuito de retroalimentación es neural en vez de humoral y se ha comprobado que el estímulo del asa aferente neural que viene del pezón y la mama, produce una inhibición del PIF (factor inhibidor de la prolactina) hipotálamico con el consiguiente aumento en la secreción de prolactina. También algunos experimentos sugieren que existe un factor estimulante de la prolactina (PSF) en el hipotálamo y se cree que la TRH es también un PSF (90).

Por otra parte, EDWARD (50) sostiene que la prolactina y la hormona del crecimiento son liberadas por la pituitaria, en varias especies, por intermedio de la TRH aunque esta hormona hipotalámica está principalmente comprometida con la liberación de tirotropina. Por consiguiente, la TRH posee una amplia especificidad de acción sobre la glándula pituitaria. En ratas adultas, la TRH liberará más prolactina que hormona del crecimiento pero se ha encontrado un efecto opuesto en ratas recién nacidas. La causa de este fenómeno según la edad no es clara, aunque parece ser consecuencia de una interrupción entre el sistema nervioso central y la pituitaria en estas edades tempranas debido talvez a la inmadurez del eje hipotálamo-hipofisario. La liberación de prolactina es inhibida por la Dopamina y alguna vez se creyó que este neurotransmisor puede realmente ser PIF (50).

Los valores plasmáticos de prolactina en hombres y mujeres normales no muestran diferencias significativas, siendo de 9.2 y $10.3 \mathrm{microgramos} / \mathrm{c} . c$. respectivamente (101). Es sorprendente que durante el ciclo menstrual normal no se han encontrado variaciones en las concentraciones de esta hormona. Durante el embarazo normal se ha encontrado una elevación progresiva de los niveles séricos. Igualmente, durante el período post-parto existe un rápido descenso alcanzando los niveles normales hacia la tercera semana del post-parto. Pero si hay lactancia, se observa un alza dramática y sostenida de los niveles de prolactina sérica. Por consiguiente, se puede considerar a la prolactina como una hormona lactogénica altamente potente. Además, en términos generales, los niños nacen con altos nivelès de prolactina sérica que descienden progresivamente hasta llegar a los valores basales alrededor de la sexta semana. Este hallazgo puede ser la causa de la ginecomastia observada $\tan$ frecuentemente en los recién nacidos.

\section{c) Corticosteroides.}

La corteza suprarrenal materna es más activa hacia el fín del embarazo (40) y los glucocorticoides provocan una secreción láctea precoz.

\section{d) Hormonas ováricas y placentarias.}

Los esteroides ováricos y placentarios influencian el crecimiento y la actividad se- 
cretora del tejido mamario y modifican la liberación de las hormonas de la adenohipófisis.

La telarquia o comienzo del desarrollo de los senos es la consecuencia del estímulo hormonal proveniente de los ovarios; así, los estrógenos estimulan el desarrollo de los conductos galactóforos y la progesterona produce una proliferación de los acinos glandulares. Durante el embarazo estas acciones son mucho más evidentes preparando en esta forma al seno para la acción de la prolactina y demás factores hormonales. Por otra parte, a todo lo largo del embarazo se encuentra una elevación de los niveles de la somatotropina coriónica humana (HCS) o lactógeno placentario (HPL) (61) estimulando también el crecimiento mamario y la lactogénesis (59).

\section{Amamantamiento y estímulo de succión}

E1 hábito de amamantar estimula la lactogénesis (54) siendo ambos fenómenos controlados en muchas especies por cambios endocrinos similares (98). La succión del pezón desencadena la liberación de hormonas lactogénicas incluyendo la prolactina (130) y el ACTH. El reflejo de eyección láctea se produce por liberación de ocitocina proveniente de la neurohipófisis; este fenómeno junto con la succión, produce la evacuación de la leche acumulada en la glándula mamaria estimulando además la secreción láctea.

\section{Galactopoyesis.}

El término galatopoyesis significa el mantenimiento de la lactancia ya establecida y necesita de una nutrición materna adecuada e ingestión apropiada de líquidos.

Una amplia gama de hormonas es necesaria para la galactopoyesis, e incluye prolactina, hormona del crecimiento, mineralosis, y glucocorticoides, tirozina, insulina y paratormona. Por otra parte, los esteroides ováricos no son necesarios para la galactopoyesis pero sí pueden tener efectos supresores como lo apreciamos en mujeres que ingieren píldoras anticonceptivas. Los estrógenos administrados inmediatamente después del parto inhibirán la lactancia (78)

La lactancia no se mantiene en las madres que no lactan a sus niños (58). Por consiguiente, este fenómeno está influenciado por factores sociales y psicológicos y hoy día se está realizando una campaña a nivel mundial para estimular de nuevo la costumbre de la alimentación materna.

\section{SUMARY}

Initially we made a description of the endocrinological physilogy of the implantation and the importance of the Corpus Luteum in this early stage of gestation. Then we proceeded with the placentary endocrinology and its role as the endocrine organ secretory of chorionic gonadotrophine, ovaric steroids, cortico-steroids, androgens, $\mathrm{H}$. P.L. and prostaglandins.

We emphasized the concept of the fetalplacental unit as the place where the synthesis of estriol occurs, one of the most important strogenic compunds produced during pregnancy and its value as diagnosis media of the fetal environment.

Then, we described the endocrinological changes in the mother when the placenta becomes part of her organism, which means she has a new internal secretory organ. These changes are produced in the ovaric functions, hypophysis, the thyroid and para thyroid glands, pancreas and adrenal cortex.

As the fetus reaches the terminal stage, his endocrine glands start their activity. We reiviewed the endocrine-fetal system, regarding all the classical endocrine glands (Gonads, Hypophysis, Thyroid etc.), particulary the Thymus.

Subsequently we considered the delivery, its different stages and its liberation mechanisms (autonomous motor innervation, strogens, external environment, fetal stress, ACTH, corticosteroids, mechanical estimulation, oxitocin, progesterone and prostaglandins).

The we mentioned briefly the changes observed during the Puerperium, that is the time between the delivery and the coming back of the external genitalia to its previous state before pregnancy. This period lasts 6 to 8 weeks. 
Finally, we considered the endocrinological aspects of lactancy: the lactogenesis and the influence of hyphysiary hormones in it, prolactine, glucocorticoids, and ovaric and placentary hormones; the lactancy itself, the estimulus of suction and finally "galactopyesis".

\section{RESUMEN}

Inicialmente hacemos una descripción sobre la fisiología endocrina de la implantación y la importancia que juega el cuerpo lúteo en esta fase temprana de la gestación. Seguidamente entramos a considerar la endocrinología placentaria y su papel como órgano endocrino secretor de la gonadotropina coriónica, esteroides ováricos, corticosteroides, andrógenos, HPL y protaglandinas. Hacemos hincapié en el concepto de la unidad feto-placentaria como entidad sintetizadora del estriol, el más importante de los compuestos estrogénicos producidos en el embarazo y su valor como medio diagnóstico del ambiente fetal.

Posteriormente se describen los cambios endocrinos que sufre la madre al incorporarse la placenta a su organismo, lo cual significa que tiene un nuevo órgano secretor interno. Estos cambios se realizan en su función ovárica, en su hipófisis, en su tiroides, paratiroides, páncreas y corteza suprarrenal.

A medida que el feto alcanza su término, sus glándulas endocrinas empiezan a mostrar actividad. Se revisa entonces el sistema endocrino-fetal referente a todas las glándulas endocrinas clásicas (gon adas, hipófisis, tiroides, etc.) y en particular al timo.

A continuación se entra a considerar el parto, sus diferentes períodos y sus mecanismos desencadenantes (inervación motora autónoma, estrógenos, ambiente externo, stress fetal, ACTH, corticosteroides, estimulación mecánica, ocitocina, progesterona y prostaglandinas).

Después mencionamos brevemente los cambios que se observan el puerperio o sea el tiempo comprendido entre el parto y el retorno de los genitales externos e internos de la madre a su estado previo al embarazo. Este período dura de 6 a 8 semanas.

Finalmente entramos a considerar los aspectos endocrinos de la lactancia: la lactogénesis y la influencia que sobre ella tienen las hormonas hipofisiarias, la prolactina, los glucocorticoides y las hormonas ováricas y placentarias; el amamantamiento y estímulo de succión, y por último, la galactopoyesis.

\section{REFERENCIAS}

1. ABRAHAMS, V.C., LONGWORTH, E. P., \& THEOBALD, G. W.: Potentials evoked in the hypothalamus and cerebral cortex by electrical stimulacion of the uterus. Nature, London, 203, 654-659, 1964, cit. por (53).

2. ABRAHAMS, C. V. \& TEARE, J. L.: Peripheral pathways and properties of uterine afferents in the cat. Can J. Physiol. Pharmacol., 47, 576-577, 1969, cit. por (53).

3. ACETO, T., BATH, R.E. BRUCK, E., SCHULZ, R.B. and PEREZ, R.: J. Clin. Endocr. Metab,. 26:487, 1966, Cit. por (18).

4. AITKEN, E. H., Preedy, J.R.K., Eaton, B. and SHORT, R. V.: Estrogen and Progesterone levels on foetal and maternal plasma at parturition. Lancet, 2: 1096, 1958, Cit. por (69).

5. ALBERT, A., and BERKSON, J.: A clinical bioassay for chorionic gonadotropin. J. Clin. Endocr. 11: 805, 1951, cit. por (69).

6. ALEXANDER, D. P., BRITTON, H. G., FORSLING, M. L., NIXON, D. A. \& RATCLIFFE, J. G.: The concentrations of adrenocorticotrophin, vasopressin and oxytocin in the foetal and maternal plasma of the sheep in the latter half of gestation. J. Endocr., 49, 179-180, 1971, cit. (53).

7. AMENOMORY, Y:, CHEN, C. L. \& MEITES, J.: Serum prolactin levels in rats durin different reproductive states. Endocrinology, 86, 5061510, 1970, cit. (55).

8. AMOROSO, E. C.: Ann. d' Endocr., 16: 435,1955 , cit. (18).

9. ANDERSON, A. B. M., LAURENCE, K.M., DAVIES, K., CAMBELL, H. \& TURNBULL, A. C.: Fetal adrenal weight and the cause of premature delivery in human pregnancy. J. Obstet. Gynaec. Br. Commonw., 78, 481-488, 1971.

10. BASSET, M. \& THORNBURN, G.D.: Foetal plasma corticosteroid and the initiation of parturition in sheep. J. Endocr., 44, 285-286, 1969, cit. (53). 
11. BEARN, J. G.: Endocrinology, 80: 979, 1955 , cit. (18).

12. BEDFORD, C. A., CHALLIS, J. R. G., HARRISON, F. A. \& HEAD, R. B.: The role of oestrogens \& progesterone in the onset of parturition in various species. J. Reprod. Fert., Suppl. 16. 1-23, 1972.

13. BEISCHER, N. A., BARGAVA, V. L., Brown, J. B. \& SMITH, M. A.: The incidence and significance of low oestriol excretion in an obstetric population. J. of Obstet. \& Gynec. of the British Comm., 75, 1024, 1968.

14. BELING, C.: Estrogens. In Endocrinology of pregnancy, ed. Fuchs, F., \& Klopper, A., pp. 32-65, New York, Harper \& Row, 1971, cit. (36).

15. BINNS, W., JAMES, L. F. \& Shupe, J. L.: Toxicosis of Veratrum Californicum in Ewes and its relationship to a congenital deformity in lambs. Ann. N. Y. Acad. Sci, iii, 571-576, 1964, cit. (53).

16. BLATCHLEY, F. R., NONOVAN, B. T., POYSER, N. L., HORTON, E. W., THOMPSON, C. J., \& LOS, M.: Identification of prostaglandin $\mathrm{F}_{2} \propto$ in the utero-ovarian blood of guinea pig after treatment with oestrogen. Nature, Lond., 230. 243-244. 1971 . cit. (53).

17. BLOCH, K.: The biological conversion of cholesterol a pregnandiol. J. Biol. Chem., 157: 661,1945 , cit. (69).

18. BOTELLA-LLUSIA, J.: Endocrinology of woman. W. B. Saunders Co., Philadelphia, London, Toronto, pp. 393-482, 1973.

19. BROOKS, C. M., ISHIKAWA, T., KOUZUMI, K. \& LU, H. H.: Activity of neurones in the paraventricular nucleus of the hypothalamus and its control. J. Physiol., Lon., 182, 217-231, 1966 , cit. (53).

20. BROTANER, V., HENDRICHS, C. H. \& YOSHIDA, T.: Importances of changes in uterine blood flow in initiation of labor. Am. J. Obstet. Gynec., 105, 535-546, 1969.

21. BROWN, J. B.: Urinary excretion of oestrogen during pregnancy, lactation and the reestablishment of menstruation. Lancet 1, 704, 1956.

22. BUNCHER, C. R.: Cigarrette smoking and duration of pregnancy. Am. J. Obstet, Gynec. 103, 942-946, 1969.

23. BURT, R. L., \& PULLIAN, R. E.: Obstet, Gynec., 14: 519, 1959, cit. (18).

24. CEKAN, Z.: Steroid biosynthesis in the human foeto-placental unit. Res. in Reprod., 4, 3, May. 1972.

25. COCH, J. A., BROVETTO, J., CABOT, H. M., FIELITE, C. A. \& CALDEYRO-BARCIA, R.: Ocytocin equivalent activity in the plasma of women in labor and during the puerperium. Am. J. Obstet. Gynec., 91, 10-17, 1965.

26. CONTOPOULOS, A. N. \& SIMPSON, M. E.: Endocrinology, 64: 1023, 1959, cit. (18).
27. CORNBLATH, M., et al.: J. Clin. Endocr. Metal., 25: 209, 1965, cit. (18).

28. GRAFT, I., WYMAN, H. \& SOMMERVILLE, I. F.: Seral analysis of plasma progesterone and pregnandiol in human pregnancy. J. Obstet. Gynaec. Br. Commonw., 76, 1080-1089, 1969.

29. CROSS, B. A.: Neurohypophyseal control of parturition. In recent Progress in the Endocrinology of Reproduction, ed Lloyd, C. W., pp 441453, New York \& London, Academic Press, 1959.

30. CSAPO, A.: The four direct regulatory factors of myometrial function. In Progesterone: its regulatory effect in the myometrium, ed. Wolstenholme, G. E. W. \& Knight, J. pp 13-42, 1969.

31. CSAPO. A. \& WOOD L.: The endocrine control of the initiation of labor in the human. In Recent advances in Endocrinology, 8th. Ed., ed. James, V. H. T. pp 208-239, 1968.

32. CSAPO, A.: The regulatory interplay of Progesterone and Prostaglandin $\mathrm{F}_{2}$ in the control of the pregnant uterus. In problems in Reproduction, Vol I, ed. Josimovitch, J. B., New York, 1972.

33. CHANG, M.C.: J; Exper. Zool., 128: 379, 1955 , cit. (18).

34. CHANG, M. C., \& YANIMAGICHI, R.: J. Exper. Zool., 154: 173, 1963, cit. (18).

35. CHARD, T., HUDSON, C. N., EDWARD, C. R. W. \& BOYD, N. R. H.: Release of oxytocin and vasopressin by the human fetus during labor. Nature, Lond., 234, 352-354, 1971.

36. CHARD, T.: Valoración hormonal de las funciones fetales y placentarias. En Ginecología y Ostetricia, Temas Actuales, Medicina Fetal, Cap. V, pp 85-103, Abril 1974, Interamericana, México.

37. DASLER, C. G., \& Kyank, H.: Gynaecologia, 155: 175, 1963, cit. (18).

38. DAUGHADAY, W. H.: The Adenohypophysis, Chapter 2, pp 46-48, In Tex tbook of Endocrinology, Ed. Robert Williams, 5th. Ed. W. B. Saunders C., 1974.

39. DAVIS, M. E. \& FUGO, N. W.: Effects of various sex hormones on the excretion of pregnandiol early in pregnancy. Proc. Soc. Exp. Biol. Med., 65: 283, 1947, cit. (69).

40. DENAMUR, R.: Hormonal control of lactogenesis J. Dairy Res., 38, 237-264, 1971. cit. (55).

41. DICZFALUSY, E. \& MANCUSO, S.: Oestrogen Metabolism in Pregnancy. In Foetus and Placenta, ed. Klopper, A. \& Diczfalusy, E. pp 191-248, Oxford \& Edinburgh, 1969.

42. DICZFALUSY, E.: Endocrinology of the Foetus. Acta Obst. Gynec. Scand, 41, Suppl. $1,45-85,1962$. 
43. DICZFALUSY, E.: Endocrinological funtions of the human foetoplacental unit.Fec. Proc., 23,'791-798, 1964.

44. DICZFALUSY, E,. op. cit. (41).

45. DICZZFALUSY, E.: Acta Gin., 16 (Suppl.), 7, 1965, cit. (18).

46. DIECKMAN, W. J., et al.: Am. J. Obstet. Gynec., 60: 1043, 1960, cit. (18).

47. DOE, R. P., DICKINSON, P., ZINNE, H. H, M. \& SEAL, U. S.: J. Clin. Endocr., 29: 757, 1969, cit. (18).

48. DOWLING, J. T., FREINKEL, N., \& INGBAR, S. H.: J. Clin. Endocr. Metab., 21: 779,1961 , cit. (18).

49. DUHRING, J. L.: Feto en peligro. Trib. Med. LVII, No. 620: 10, 1976.

50. EDWARD, R. G.: The nature of prolactin secretion. Res. in Reproduc., 9, 2, March, 1977. 51. EMERMAN, S., DANCIS, J., LEVITA, M., WIQVIST, N., \&DICZFALUSY, E.: J. Clin. Endocr, Metab., 25: 178, 1965.

52. FERGUSON, J. K. W.: A study of the motility of the intact uterus at term. Surgery, Gynec. Obstet, 73, 359-366, 1941, cit. (53).

53. FINDLAY, A. L. R.: The Control of Parturition. Res. in Reprod. 4, 5, 1972.

54. FINDLAY, A. L. R.: The role of suckling

in lactation. In Lactogenic Hormones, Fetal nutrition and lactation, ed. Josimivich, J. P., Reynolds, M., \& Cobo, E., pp 453-477, New York, 1974.

55. FINDLAY, A. L. R.: Lactation. Res. in Reprod., Vol 6, No. 6, Nov., 1974.

56. FINDLAY, A. L. R., op. cit. (55).

57. FISCH, L., SALA, N. L., \& SCHWARCZ, R. L.: Effect of cervical dilatation upon uterine contractility in pregnant woman and its relation to oxytocin secretion. Am. J. Obstet. Gynec., 90, 108-114, 1964.

58. FOMON, S. J.: Infant nutrition, 2nd. Ed., Philadelphia, Saunder, 1974.

59. FORSYTH, I. A.: The role of primate prolactins and placental lactogens in lactogenesis: The initiation of milk secretion at parturition, ed. Reynold, M. \& Folley, S. J. pp 195-205, Philadelphia, University of Pennsylvania Press, 1969.

60. FRANDSEN, J. A. \& ST AKEMANN, G.: The site of production of oestrogenic hormones in human pregnancy, II Experimental investigations on the role of the foetal adrenal. Acta Endocr., 43, 184-194, 1963.

61. FRIESEN, H., BELANGER, C., Guyda, G., \& HWANG, P.: The synthesis and secretion of placentral lactogen and pituitary prolactin. In, Lactogenic Hormones, ed. Wolstnhome, G. E. \& Knight, J. pp 83-103, Edinburgh and London: Churchill Livingstone, 1972.
62. Garcia-Conti, F.: Análisis comparativo de la exactitud de las pruebas biológicas e inmunológicas para el diagnóstico precoz del embarazo (para ser publicado).

63. GEMZELL, C. A.: J. Clin. Endocr. Metab., 13: 898,1963 , cit. (18).

64. GIMLETTE, T. M. D., \& Pifanelli, A.: J. Clin. Path., 21: 767, 1968.

65. GITLIN, D., KUMATE, J., \& MORALES, C.: J. Clin. Endocr. Metab., 25: 1599, 1965, cit. (18).

66. GRATTAROLA, R., \& LI, C. H.: Endocrinology 65: 802, 1959, cit. (18).

67. GREENE, J. W., \& TOUCHSTONE, J. C.: Urinary estriol as an index of placental function: A study of 279 cases. Am. J. Obstet. Gynec., 85: $1,1963$.

68. GREEN, M.: Endocrinology, 65, 178, 1959, cit. (18).

69. GREENHILL, J. P., \& FRIEDMAN, E. A.: Biological Principles and Modern Practice of Obstetrics. W. B. Saunders Co. Philadelphia, London, Toronto, pp 55-74, 1974.

70. GREISS, F. C., \& GOBBLE, F. L.: Effects of sympathetic nerve stimulation of the uterine vascular bed. AM. J. Obstet. Gynec., 97, 962-967, 1967.

71. GROSVENOR, C. E., \& MENA, F.: Neural and Hormonal Control of milk secretion and milk ejection. In Lactation: A comprehensive Treatise, ed. Larson, B. L., \& Smith, V. R., New York \& London, Academic Press, 1974.

72. GUYTON, A. C.: Tratado de Fisiología Médica, 4a. ed. Interamericana, pp 132, 10421044, 1971.

73. HARNESS, R. A., and LOVE, D. N.: Acta Endocr., 51: 526, 1966, cit. (18).

74. HAWKER, R. W.: Endocrinology, 52: 117, 1953, cit. (18).

75. HEYS, R. F., SCOTT, J. S., OAKEY, R. E., \& STITCH, S. R.: Urinary oestrogen in late pregnancy. Oestriol excretion as a guide to impending foetal death before term. Lancet, i, 328, 1968.

76. HODGES, R. E., et al: J. Clin. Endocr. Metab., 15: 661, 1965, cit. (18).

77. ISRAEL, S. L., STROUP, P. E., SELIGSON, H. T., \& SELIGSON, D.: Epinephrine \& norepinephrine in pregnancy \& labor. Obstet. Gynec., N. Y., 14, 68-71, 1959.

78. JEFFCOATE, T. N. A., MILLER, J., \& TINDALL, V. R.: Puerperal thromboembolism. Br. Med. J. i, 378-379, 1969.

79. JOSIMOVICH, J. B., \& MacLAREN, J. A.: Presence in the human placenta and term serum of a highly lactogenic substance inmunologically related to pituitary growth hormone. Endocrin. 71: 209, 1962. 
80. JOST, A.: In Probleme der fetalen Endokrinologic, ed. H. Nowakowsky, Berlin, Springer, 1957, cit. (18).

81. JOST, A., Pick, P., Maniey, J. and Legrand, C.: Acta Endocr., 43: 618, 1963, cit. (18).

82. KALKHOFF, R. D., JACOBSON, M., \& LEMPER, D.: J. Clin. Endocr., 30: 24, 1970.

83. KAPLAN, S. L., \& GRUNBACH, M. M.:

J. Clin. Endocr. Metab., 25: 1360, 1965, cit. (18).

84. KARIM, S. M. M.: Physiological roleoof prostaglandins in the control of partirition and menstruation. J. Reprodu. Fertil. Suppl. 16, 105 119,1972 .

85. KARIM, S. M. M.: Appearance of prostaglandin $\mathrm{F}_{2} \propto$ in human blood during labor. Br. Med. J., iv, 618-621, 1968.

86. KARIM, S. M. M., \& SHARMA, S. D.: The effect of ethyl alcohol on prostaglandins $\mathrm{E}_{2}$ and $\mathrm{F}_{2} \propto$ induced uterine activity in pregnant woman. J. Obstet. Gynaec. Br. Commonw., 78, 251-254, 1971 .

87. KNOBIL, E., \& JOSIMOVITH, J. B.: Ann. N. Y. Acad. Sci., 75: 895, 1959.

88. LANMAN, J. Y. \& DINERSTEIN, J.: Enducrinology, 64: 494, 1959, cit. (18).

89. LANMAN, J. T.: Fetal Endocrinology in Pregnancy in Physiology of Prematurity, ed. J. T. Lanman, Vol. I, New York, The Josiah Macy Foundation, 1957.

90. L'HERMITE, M., VANHAELST, L., COPINSCHI, G., LECLERCQ, R., GOLDSTEIN, J., BRUNO, O. D., * ROBIN, C.: Prolactin release aftter injection of thyrotrophin-releasing in man, Lancet 1: 763, 1972. Cit. en Year Book of Endocrinology, pp 25, 1973.

91. LIGGINS, G. C.: Premature parturition after infusion of corticotrophin or cortisol into foetal lambs. J. Endocr., 42, 323-329, 1968.

92. LIGGINS, G. C.: Premature delivery of foetal lambs infused with glucocorticoids. J. Endocr., 45, 515-523, 1969.

93. LLAURO, J. L., RUNNEBAUM, B., \& ZANDER, J.: Progesterone in human peripheral blood beforen during and after labor. AM. J. Obstet. Gynec., 101, 867-873, 1968.

94. MARSHALL, F. H. A., \& CHASSAR MOIR, J.: Parturition. In Marshall's Physiology of Reproduction, Vol. II, ed. Parkes, A. S. pp 496-524, London, 1952, cit. (53).

95. MARSHALL, J. M.: Vertebrate smooth muscle. In Medical Physiology, Vol. II, pp 1172 -1199, Saint Louis, C. V. Mosby, 1968.

96. Meites, J., \& CLEMENS, J. A.: Hypothalamic control of prolactin secretion. Vitams. Horm., 30, 166-22 1, 1972.

97. MILIC, A. M., \& ADAMSONS, K.: The relatioship between anencephaly and prolonged pregnancy. J. Obstet. Gynec. Br. Commonw., 76, 102-111, 1969.
98. MOLTZ, H., \& LEON, M.: Birth processes and maternal behavior in some familiar laboratory mammals. In Modern Perspectives in PsychoObstetrics, ed. Howells, J.G., pp 3-30, Edinburgh: Oliver \& Boyd, 1972.

99. NAKANISHI, H., \& WOOD, C.: Cholinergic mechanism in the human uterus. J. Obstet. Gynaec. Br. Commonw. 78, 716-723, 1971.

100. NEWTON, N., PEELER, D., \& NEWTON

M.: Effect of disturbance on labor. Am. J. Obstet. Gynec., 101, 1098-1102, 1968.

101. NOEL, G. L., SUH, H. K., STONE, J. G., \& FRANTZ, A. G.: Human prolactin and growth horm one release during surgery and other conditions of stress. J. Clin. Endocrinol. 35: 840, 1971.

102. OLIN, P., VECCHIO, G., ERKHOLM, R., \& ALMQVIST, S.: Endocrinology, 86: 1041, 1970, cit. (18).

103. PEARLMAN, W.H.: $16^{-3}$ Hprogesterone metabolism in adrenald pregnancy and in oophorectomizec-hysterectomized women. Biochem. J., 67: $1,1957$.

104. PINTO, R. M., LEON, C., MAZZOCCO, N. \& SCASSERRA, J.: Action of estradiol-17, beta at term \& at onset of labor. Am. J. Obset. Gynec., 98,540-546, 1967.

105. PLOTZ, E. J., \& DAVIS, M. E.: Distribution of radioactivity in human maternal and fetal tissue following administration of $\mathrm{C}^{14-4}$ progesterone. Proc. Soc. Exp. Biol. Med. 95:92, 1957.

106. REID, D. E.: A. textbook of Obstetrics, W. B. Saunders Co, Philadelphia, London, pp 150, 1962.

107. RIVAROLA, M. A., FOREST, M. G., \& MIGEON, C. J.: J. Clin. Endocr. Metab., 28: 34, 1968.

108. ROBERTS, J. S., \& SHARE, L.: Effects of progesterone and estrogen on blood levelsof oxytocin during vaginal distention. Endocrinology, 84, 1076-1081, 1969.

109. ROBERTSON, H. A., \& FALEONER, J. R.: J. Endocr., 22: 133, 1961, cit. (18). 110. ROBINSON, K. W., HAWKER, R. W., \& ROBERTSON, P. A.: J. Clin. Endocr. Metab., 17: 320, 1957, cit. (18).

111. ROBINSON, M.: Failing lactation: Study in 1.100 cases. Lancet 1: 66, 1943, cit. (69).

112. ROSENTHAL, H. E., SLAUNWHITE, W. R., \& SANDBERG, A. A.: J. Clin. Endcr., 29: $352,1969$.

113. ROY, E., \& BROWN, J. B. 1957: Cit. by Loraine, J. A. Ciba Foundation Colloq. Endocr., 11: 335,1957 , cit. (69).

114. RUSSE. M. W. \& MARSHALL, J. M.: Uterine response to adrenergic nerve stimulation in the guinea pig. Biology of Reproduction, 3, 13-22, 1970. 
115. RYAN, K. J.: Metabolism of C-16- oxygenated steroids by the human placenta. The formation of Estriol. J. Biol. Chem. 234: 2006, 1959. cit. (69).

115a. RYAN, K. J.: Endocrine control of gestational lenght. Am. J. Obstet. Gynec., 109, 299-306, 1971.

116. SALA, N. L., SCHUWARCZ, R. L. et al: Effect of epidural anesthesia upon uterine contractility induced by artificial cervical dilatation in human pregnancy. Am. J. Obstet. Gynec., 106, 26-29, 1970.

117. SALHANICK, H. A., KIPNIS, D. M., \& VANDEWIELE, R. L.: Effectsoff gonadal hormones and contraceptive steroids, New York, Plenum Press, 1969.

118. SCHALCH, D. S., \& REICHLIN, S.: Endocrinology, $79: 275,1966$, cit. (18).

119. SCHMIDT, I. G., \& HOFFMANN, R. A.: Endocrinology, 55: 125, 1954, cit. (18).

120. SCHWARTZ, T. B.: Prolactin, Year Book of Endocrinology. ed. Theodore B. Schwartz, W. G. Ryan, \& F. O. Beeker, pp 7-24, 1973.

121. SCHWERS, J., ERIKSSON, G., \& DICZFALUSY, E.: Acta Endocr., 49: 65, 1965, cit. (18).

122. SCIARRA, J. J., KAPLAN, S. L., \& GRUMBACH, M. M.: Localization of antihuman growth hormone serum within the human placenta: Evidence for a human chorionic "growth hormone-prolactin". Nature, 199: 1005, 1963.

123. SHABANAH, E. H., TOTH, A., OMAY, Y. \& MAUGHAN, G. B.: The role of the autonomic nervous system in uterine contractility and blood flow. V. Interrelationship of estrogen, progesterone, and the pituitary tropihc hormones in the control of myometrial function. Am. J. Obstet. Gynec, 100, 974 -980, 1968.

124. SHARMAN, A.: Menstruation after chilbirth. J. Obstet. Gynaec. Brit. Empire 58: 440,1951 , cit. (69).

125. SHARMAN, A.: Ovulation after pregnancy. Fertil. Steril. 2: 371,1951 , cit. (69).

126. SHELESNYAK, M. C.: Acta Endocr. 50: 452,1965 , cit. (18).

127. SHEPARD, T. H.: J. Clin. Endocrinology, $27: 945,1967$, cit. (18).

128. SIERSBACK-NIELSEN, K., \& MOLHOLMHANSEN, J.: Acta Endocr., 60: 423, 1969 , cit. (18).

129. THIEDE, H. A., \& CHOATE, J. W.: Chorionic gonadotropin localization in the human placenta by immunofluorescent staining: II Demostration of HCG in the trophoblast and amnion epithelium of immature and mature placentas. Obstet. Gynec. 22: 433, 1963.

130. TINDAL, J. S.: Hypothalamic control of secretion and release of prolactin. J. Reproduc. Fert., 39, 437-461, 1974.
131. TRAYNER, I. M., et al: J. Endocr., 37 . 443, 1967, cit. (18).

132. VAN ARSDEL, P. P.: J. Clin. Endocr. Metab., 15: 680, 1955, cit. (18).

133. VAN DEN DRIESCHE, R.: In Oxytocin, ed. Caldeyro-Barcia \& Heller. Oxford, Pergamon Press, 1961, cit. (18).

134. VORHERR, H.: The pregnant uterus: process of labor, puerperium and lactation. In Biology of Gestation, Vol I, pp 426448 , 1968, New York \& Lodon, Academic Press, cit. (53). 135. WAGNER, G., TRASBOL, I., \& MELCHIOR, J. C.: Acta Endocr., 47; 549, 1964, cit. (18).

136. WALLACE, S. J. \& MICHIE, E. A.: A follow-up study of infants born to mothers with low oestriol excretion during pregnancy. Lancet, II, 560, 1966.

137. WALTON, R. L.: Pedriatrics, 13: 227, 1954 , cit. (18).

138. WHO SCIENTIFIC GROUP: Endocrine regulation of human gestation. WHO Tech. Rep. Ser. No. 471,1971 , cit. (24).

139. WISLOCKI, G. B. \& BENNETT, H. S.: The histology and cytology of the human and monkey placenta with special reference to the trophoblast. Am. J. Anat. 73: 335, 1943, cit. (69).

139a. WU, C. H., TOUCHSTONE, J. C., \& FLICKINGER, G. L.: Am. J. Obstet. Gynec., 102: 862, 1968.

140. YANNONE, M. E., MacCURDY, J. R. \& GOLDFEIN, A.: Plasma progesterone levels in normal pregnancy, labor, and the puerperium: II Clinical data. Am. J. Obstet. Gynec, 101, 1058 1061,1968 , cit. (36).

141. YOUSEM, H., SEITCHIK, J. \& SOLOMON, D.: Maternal Estriol excretion and fetal dysmaturity, Obstetrics \& Gynecology, 28, 491, 1966.

142. ZANDER, J.: Progesteron in menschlichem blut und Geweben: I Progesteron im peripheren venösem Blut der Frauklilin. Wschr. 33: 697, 1955, cit. (69).

143. ZLATNIK, F. J., \& FUCHS, F.: A controlled study of ethanol in threatened premature labor. AM. J. Obstet. Gynec., 112, 610; 612, 1972.

144. ZUSPAN, F. P.: J. Clin. Endocr., 30: 357,1970 , cit. (18). 